\title{
UNA ADAPTACIÓN DE ENREDO: LA ILUSTRE FREGONA DE GABRIEL IBÁÑEZ Y ANTONIO COTANDA
}

\author{
VICTORIA ARANDA ARRIBAS \\ Universidad de Córdoba*
}

Resumen

Este artículo analiza la miniserie La ilustre fregona (TVE, 1978), adaptación de Gabriel Ibáñez, en alianza con el guionista Antonio Cotanda, del relato homónimo incluido en las Novelas ejemplares (1613) de Cervantes. Se pasa revista aquí a las transformaciones derivadas del cambio de medio y de época, profundizando en las huellas de la comedia de enredo en el último capítulo de esta reescritura audiovisual.

Palabras clave: TVE, novela, La ilustre fregona, Novelas ejemplares, adaptación, Cervantes.

\section{AN ADAPTATION OF «ERRORS»: LA ILUSTRE FREGONA BY GABRIEL IBÁÑEZ AND ANTONIO COTANDA}

Abstract

This article analyzes the miniseries La ilustre fregona (1978), directed by Gabriel Ibáñez with Antonio Cotanda and adapted from the homonymous tale included in the Exemplary novels (1613) by Cervantes. Through the comparative study of both works, I will reflect on the transformations triggered by the medium and epoch change in the adaptation. Furthermore, special attention will be paid to the influence of the "comedia de enredo" (comedy of errors) in the last episode of this audiovisual rewrite.

Keywords: TVE, novela, La ilustre fregona, Exemplary Novels, adaptation, Cervantes.

* Este artículo se inscribe en el marco del Proyecto de Excelencia I+D+i del MINECO La novela corta del siglo XVII: estudio y edición (y III) (FFI2017-85417-P) y ve la luz gracias a la financiación de una beca FPU concedida por el Ministerio de Educación, Cultura y Deporte. Sin la impagable ayuda del Fondo Documental de Radio Televisión Española (RTVE) no habría sido posible el visionado de la serie Novela y, en consecuencia, la redacción de este artículo. 
Entre los trasvases audiovisuales de las Novelas ejemplares (1613), los cuatro de La ilustre fregona son los que más dificultades han sufrido para llegar a buen puerto. Conservamos, en primer lugar, un guion de 1926, impreso en Toledo y firmado por un tal Francisco Carrillo Casado. Ignoro si llegó a convertirse en material cinemático, pero no he encontrado indicios de que así fuera. A este respecto, valdría considerar la mención en algunos lugares (Lázaro, 2017: s. p.) de un filme estrenado en 1927, bajo la dirección de Carlos Emilio Nazarí, controvertido autor de origen chileno con residencia en Sevilla ${ }^{1}$. No obstante, tampoco la prensa de la época se hizo eco de dicha película, ni parece que la produjera el estudio del araucano (Film Nazarí). Todo ello invita a conjeturar que se gestó a partir de la fusión de otra Ilustre fregona de 1927, esta vez rodada por el portorriqueño Armando Pou, e Historia de un taxi, largometraje del mismo Nazarí proyectado aquel año y que, por su cercanía en los catálogos del cine mudo español, alguien debió de confundir². Lo que está claro es que hoy nadie duda de la existencia de aquella obra de Pou, de la que han sobrevivido algunas escenas ${ }^{3}$.

Desde que la televisión conquistara nuestros hogares, se han emitido solo tres recreaciones de La ilustre fregona. El 29 de abril de 1963, la entonces única cadena nacional programó la dirigida por Pedro Amalio López. Por desgracia, también se ha perdido. La siguiente (Luis Sánchez Enciso, 1973), grabada para Hora 11, es la única que pervive sin mutilaciones, aunque -si se me permite la franqueza- probablemente sea también la menos atractiva. La tercera y última, objeto de este trabajo, se cifra en cinco capítulos destinados al espacio Novela de TVE. Este fue uno de los formatos más aplaudidos entre 1964 y 1975, y permaneció en antena durante casi dos décadas: desde 1962 a 1978 (López, 2009: 19). La audiencia disfrutó así de «transposiciones» de obras de muy diversa

${ }^{1}$ Sobre este curioso personaje de la época silente del cine español, cf. Utrera (2000).

${ }^{2}$ Aunque pueda sonar extraño, este no sería el primer caso de creación de «títulos fantasmas» a partir de la mezcla de otros en el corpus cinematográfico de las Ejemplares. Seguin (2015) descubrió que una supuesta Gitanilla rodada por el gran Louis Feuillade no era más que una ilusión a partir de la alianza de otra película del director francés, L'enfant de la roulotte (1914), de atmósfera zíngara y traducida en España con el título del texto cervantino, y un guion de la casa Gaumont que adaptaba la primera novela de la colección del complutense y pudo haber escrito el propio Feuillade.

${ }^{3}$ Pou fue un reconocido operador de cámara de origen boricua. Se encargó de esta cinta junto con los hermanos Zameño, fundadores de la productora Venus Film Española, cuya filmografía se limitó a este único largo. Véase Aranda Arribas (2017). 
índole 4 . Al principio, el programa atendió por Novela del lunes y sus episodios solo se emitían el primer día de la semana, en horario de sobremesa y con un metraje de 45 minutos (García de Castro, 2002: 31). Es lo que sucedió con La ilustre fregona (1963) de Pedro Amalio López. Después, su frecuencia se ampliaría a los cinco días laborables, pasando entonces a llamarse Novela y ofreciendo asimismo historias seriadas, en tandas de cinco capítulos, que en ocasiones alcanzaron la veintena (es el caso de la Ana Karenina de Fernando Delgado, 1975) 5 .

Según García de Castro (2002: 32), «con este nuevo formato [...] se pretendió trasladar en televisión las normas del serial radiofónico para montar un capítulo diario y poder emitir una novela a la semana». Tamaño éxito favorecería a su vez -ya en la parrilla nocturna- el nacimiento de Novela II, dentro de la cual se inscribe la versión de Gabriel Ibáñez y Antonio Cotanda, ambos sin trabajos reseñables fuera de la pequeña pantalla. La única noticia que tenemos del segundo, aparte de la que nos atañe, es su participación como guionista (La cabaña, 1966) en la mítica serie de Narciso («Chicho») Ibáñez Serrador Historias para no dormir (1966-1982)6 . Lástima que no dispongamos de más pistas, pues, como veremos, su «reescritura» de la octava de las Ejemplares supone lo mejor de este par de capítulos ${ }^{7}$.

En cuanto a Ibáñez, su firma como director asoma en diferentes seriales desde 1976 hasta 1985: El teatro (Judas, 1975; Los caciques, 1976), Ficciones (El jardín de los hipopótamos, 1981; Adiós, Lorenzo, 1981) y

\footnotetext{
${ }^{4}$ Wolf (2001: 15-16) rechaza el término «adaptación», ya que este «tiene también una [implicación] material [...]. La cuestión se plantea en términos de que el formato de origen -literatura- "quepa" en el otro formato -cine- [...]. Desde mi punto de vista, la denominación más pertinente es la de "transposición", porque designa la idea de traslado, pero también la de trasplante, de poner algo en otro sitio, de extirpar ciertos modelos, pero pensando en otro registro o sistema».

${ }^{5}$ Para esta serie se realizó además, en 1966, una reescritura de El licenciado Vidriera cervantino: Los hombres de cristal (Fernando Delgado).

${ }^{6}$ Disponible en línea: <https:/www.imdb.com/name/nm7272884/> (consulta: 30 de diciembre de 2019). El abuelo de Chicho por línea paterna, de origen argentino y padre del reputado actor Narciso Ibáñez Menta, se apellidaba Cotanda de segundo. Al ser este un nombre poco convencional, no descarto que hubiera algún lazo familiar entre ambos artistas.

${ }^{7}$ La reescritura es «una forma de hipertextualidad consistente en la transposición de un texto dentro de otro que lo repite al tiempo que lo transforma, con una intención seria -y no cómica- que puede ir desde la actualización y la reivindicación a la crítica y la oposición» (Pardo García, 2010: 48).
} 
reiteradas participaciones en Novela (Juanita la Larga, 1971; La hija del mar, 1976; El caso del malentendido, 1977). Trece años antes de La ilustre fregona realizó para TVE Aventuras de Don Quijote (1965), por lo que su vínculo con el Manco de Lepanto no se redujo a la de la octava de las Ejemplares ${ }^{8}$. Sospecho que ambos creadores se dedicaron luego a oficios alejados del audiovisual, pues no hay más noticias de su carrera televisiva después de 1985.

En los capítulos de Novela, Teresa Rabal dio vida a Constanza, Emilio Gutiérrez Caba -Tomás (Rodaja) en El licenciado Vidriera de Los libros (Jesús Fernández Santos, 1974) ${ }^{9}$ - interpretó a Tomás de Avendaño y Luis Varela a Diego de Carriazo. Entre los secundarios, destacan Alejandro Ulloa y Tomás Blanco, como los padres de los héroes; Nuria Carresi, en el papel de la Señora Peregrina; Encarna Abad y Emilio Rodríguez (los dos mesoneros), José María Escuer (el Corregidor) y Mercedes Barranco y Paloma Hurtado (la Argüello y la Gallega, respectivamente). Asimismo, Marta Puig y Flora María Álvaro componen dos personajes que no aparecían con dichos nombres en el relato: Dorotea y Cristina. Pero antes de adentrarnos en estas y otras innovaciones de La ilustre fregona televisiva, será conveniente recordar la trama del original.

En Burgos, los nobles Diego de Carriazo y Tomás de Avendaño planean su fuga para probar suerte en la picaresca, ya que el primero acaba de regresar de una triunfal escapada andaluza, donde se había graduado de «maestro en las almadrabas de Zahara [...], el finibusterrae de [los rufianes]»(Cervantes, 1997: 22) ${ }^{10}$. Pronto convencerán a sus padres para que los dejen partir con la excusa de ir a estudiar a Salamanca y, una vez libres de la custodia de Pedro Alonso, su ayo, emprenden su soñado camino hacia tierras gaditanas. Durante la travesía, harán una primera parada en Toledo. Mientras descansan en una taberna, escuchan hablar de una moza de mesón conocida en toda la ciudad por su hermosura y agudeza. Movido por la curiosidad, Avendaño se afanará en conocerla y acaba enamorándose de ella. Dicho imprevisto hace que la estancia de

\footnotetext{
${ }^{8}$ Señalan González y Medina (2017: 805): «Este programa, emitido dentro del espacio Caminos y canciones, es una idea del reconocido bailaor Luis Pérez Dávila, más conocido como Lusillo (1928-2007), y se trata de un ballet filmado [de episodios seleccionados del Quijote]».

${ }^{9}$ Véase Aranda Arribas y Bonilla Cerezo (2018).

${ }^{10}$ Citaré siempre por esta edición, con la única indicación de las páginas.
} 
los pseudopícaros en la ciudad imperial se alargue más de lo apetecido por Carriazo.

La llegada de estos burgaleses a la Posada del Sevillano, donde vive y trabaja Constanza -la ilustre fregona-, coincide con la renuncia del mozo de la cebada y del aguador a sus respectivos puestos, que enseguida asumirán nuestros protagonistas, los mismos que cambian allí sus nombres por los de Tomás Pedro (Avendaño) y Lope Asturiano (Carriazo). Al tiempo que el primero porfía -sin éxito- en granjearse la voluntad de Constanza, el segundo se verá inmerso en una serie de jocosas aventuras de signo picaresco, al tiempo que huye de la afición que le muestra la ominosa Argüello, otra de las mozas de la venta.

Semanas después, arriban a la posada unos nobles que resultan ser los padres de estos caballeros. Lejos de lo que pudiera aventurarse, el encuentro no pasa de casual, pues se personaron en Toledo en busca de la hija bastarda del progenitor de Carriazo, fruto de una violación que el aristócrata había perpetrado años atrás. La madre, que nunca quiso revelar su nombre y se hacía llamar Señora Peregrina, dio a luz en aquel mesón y dejó a su retoño al cuidado de los posaderos hasta que el sujeto adecuado preguntara por ella. A su vez, les entregó un manuscrito cuarteado y también la mitad de un medallón: ambos habrían de ser completados por el individuo de turno. Después de que el señor Carriazo se confirme como aquel que aguardaban hace años, se desvela el distinguido linaje de Constanza. La novela termina con un casamiento múltiple: el de Tomás de Avendaño con la bella fregona, el de Diego de Carriazo con la hija del Corregidor de Toledo, y el de Perico, su heredero y pretendiente de Constanza, con la hermana de Avendaño.

Según decía, de la serie de Ibáñez nos han llegado solo los dos últimos capítulos, de manera que la exégesis se verá un punto limitada. Sin embargo, confío en que dicha circunstancia no reste validez a mis corolarios.

Podremos hacernos una idea del entero desarrollo de La ilustre fregona y de su estructura audiovisual gracias a las sinopsis facilitadas por la revista Tele Radio:

Capítulo I: «Don Diego Carriazo, noble señor burgalés, ha recibido una carta en la que su hijo Diego, que abandonó hace algún tiempo 
la casa paterna, le anuncia su regreso con el deseo de compartir con él su alegría; hace venir a su vecino don Juan de Avendaño, a quien acompañan sus hijos Cristina y Tomás, este último muy amigo de Diego».

Capítulo II: «Diego y Tomás llegan a la posada del Sevillano intentando conocer a la moza de la posada de quien tanto hablan; y haciéndose pasar por dos criados de señores que llegarán más tarde, se instalan en la posada».

Capítulo III: «Tomás se niega a abandonar Toledo, a pesar de los desdenes de Constanza, la maja del mesón, quien constantemente le recrimina sus ataques. La fama de Constanza llega hasta el Corregidor de la villa, que viene al mesón con deseos de conocer a la muchacha».

Capítulo IV: El posadero explica al Corregidor cómo llegó Constanza a sus vidas. Se muestra la entrada de la Señora Peregrina y su petición. De vuelta al presente, los padres de Carriazo y Avendaño dan con la hospedería. Tomás huye para no ser descubierto. Se descubre la identidad de Constanza, que abandona la venta junto a los nobles.

Capítulo V: Avendaño regresa a la posada y, luego de ver que Constanza está ausente, sale a buscarla. Carriazo publica la verdad a su padre. Dorotea, la hija del Corregidor, seduce a Carriazo. Cristina, hermana de Avendaño, se hace con el hermano de Dorotea, Perico. Avendaño vuelve junto a su padre y averigua que lo ha prometido ya con la nueva hija de Carriazo, unión que el joven burgalés rechaza hasta que descubre que se trata de Constanza ${ }^{11}$.

De acuerdo con las sinopsis de los capítulos I-III, parece que casi no hubo ampliaciones, por lo que cabe afirmar -aun sin poner la mano en el fuego- que el núcleo del desarrollo se concentró en el V, más allá de pequeñas transformaciones en el resto. Así las cosas, me dispongo a examinar aquí los episodios supervivientes, que abordaré en dos apartados: 1) las peculiaridades del capítulo IV respecto a la novela de Cervantes; $y$

${ }^{11}$ La sinopsis de los tres primeros capítulos ha sido extraída de la programación de Tele Radio, no 1902 (1978), págs. 5-6. El resumen del IV y el V -los únicos que se conservan- los he redactado yo misma. 
2) los recursos de los que se valió Cotanda en la última entrega de su Ilustre fregona para dilatar lances y personajes del texto base gracias a una trama semiindependiente que he etiquetado como «telecomedia de enredo».

\section{ACCIÓN MUTANTE: ACUERDOS Y DESACUERDOS}

Como adelantaba, lo más feliz de esta adaptación de Ibáñez y Cotanda es sin duda el guion. La factura de sus imágenes, por el contrario, no escapa de lo convencional. La cámara sigue a pies juntillas la moda normativa de la televisión de aquella época, que bebía a menudo de las tablas, pues Novela "tuvo parecidos condicionantes narrativos [que] las adaptaciones [...] de los dramáticos-teleteatro (estructura narrativa en bloques largos, grabados en tiempo real y sin manipulación del montaje, situaciones desarrolladas en escasos decorados)»(García de Castro, 2002: 31).

El atrezzo y la ambientación salen airosos y no atentan contra la verosimilitud. Se recrea una venta sin patio (al revés que en las adaptaciones de Armando Pou y Luis Sánchez Enciso) y con una especie de granero a modo de entrada (Fig. 1). Por su parte, al fondo del salón del Corregidor destaca el estrado (Fig. 2), una dependencia íntima dentro de las casas linajudas del Barroco ${ }^{12}$. Llama la atención que el tema musical dominante sea el mismo que el de la versión de Sánchez Enciso $(1973)^{13}$. Y nótese que, tal vez a zaga del realizador tetuaní, Ibáñez también usó grabados costumbristas debajo de sus créditos (Figs. 3 y 4).

${ }^{12}$ Véase Romero Díaz (2013: 259). En este caso, además, también se colocó una rueca en el centro (Fig. 3), instrumento estrechamente relacionado con el campo de la sociabilidad femenina. Véanse Gernert (2013: 229) y Rodríguez Cuadros y Haro Cortés (1999).

${ }^{13}$ Lo mismo ocurrió en otras dos transposiciones de la quinta de las Ejemplares (El licenciado Rodaja, Antonio Chic, 1973; y El licenciado Vidriera, Jesús Fernández Santos, 1974), en las que se repite la banda sonora. Intuyo que los programas literarios de RTVE eran muy dados a la retroalimentación. 

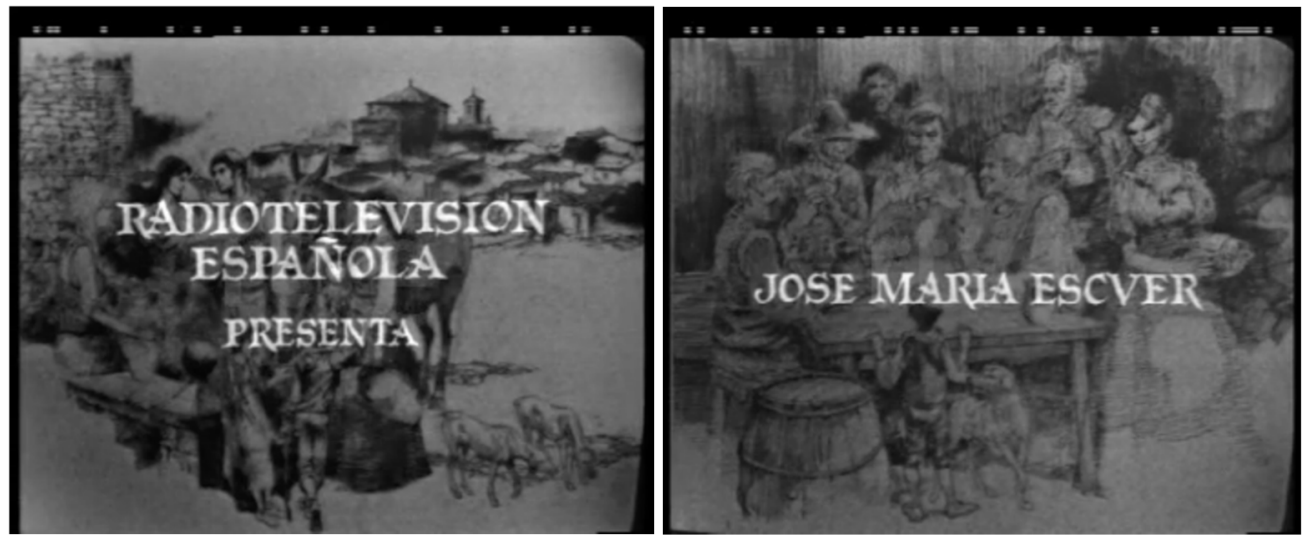

Figura 1

Figura 2

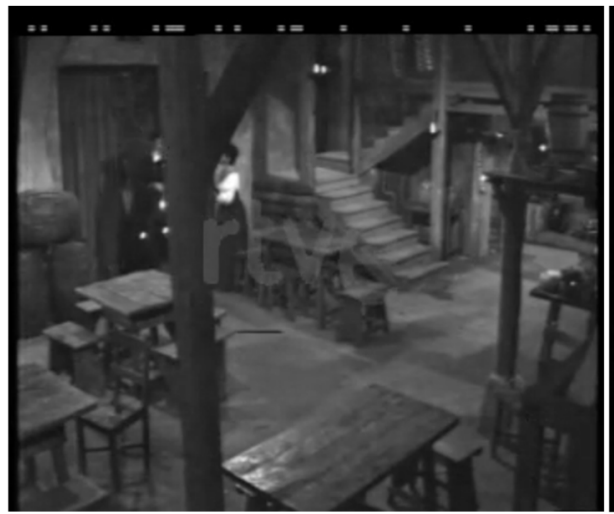

Figura 3

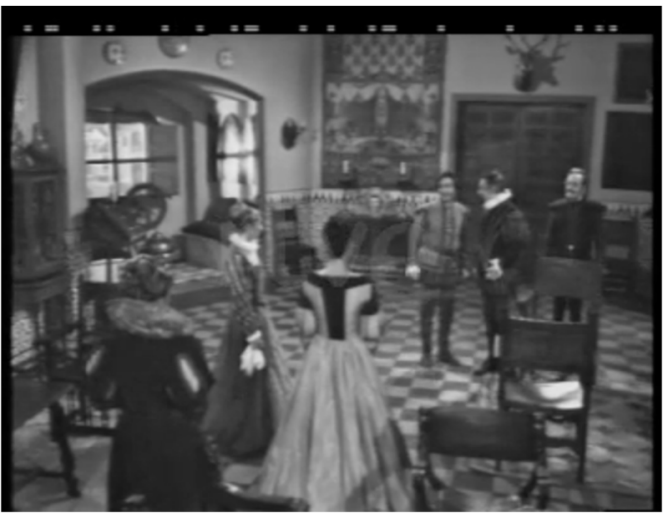

Figura 4

Pero si la dirección no brilló precisamente por su originalidad, el libreto genera nuevas lecturas sobre los cimientos de la historia de Cervantes. Los diálogos creados para las escenas no explicitadas en la novela no desentonan un ápice de los que podría haber escrito el complutense. Otras veces, Cotanda acarreó el soliloquio de un personaje o cierta información aportada por el narrador para taracearlos dentro de un intercambio de parlamentos -por ejemplo, al mostrar en el capítulo IV la llegada de la Señora Peregrina a la venta, episodio que en el relato contaba el 
mesonero ${ }^{14}$. Esta esfera metadiegética queda suficientemente detallada como para que la adaptación la recoja por medio de un flashback ${ }^{15}$. Dicha idea no constaba, sin embargo, en las otras versiones fílmicas (o en sus retazos), que pusieron la secuencia en boca del posadero. Transcribiré solo un puñado de fragmentos para evidenciar su metamorfosis en diálogo dentro del par de capítulos de TVE:

Yo y mi mujer preguntamos a los criados quién era la tal señora y cómo se llamaba, de adónde venía y adónde iba; si era casada, viuda o doncella, y por qué causa se vestía aquel hábito de peregrina. A todas estas preguntas [...] no hubo alguno que nos respondiese otra cosa sino que aquella peregrina era una señora principal y rica de Castilla la Vieja, y que era viuda y que no tenía hijos que la heredasen; y que, porque había algunos meses que estaba enferma de hidropesía, había ofrecido de ir a Nuestra Señora de Guadalupe en romería, por la cual promesa iba en aquel hábito. En cuanto a decir su nombre, traían orden de no llamarla sino la Señora Peregrina (77).

AMA. Sabéis qué mal padece.

DonCElla 1. Hace unos meses que está enferma de hidropesía. Por eso ha ofrecido ir a nuestra señora de Guadalupe en romería.

DONCELLA 2. Y por eso lleva hábito.

AMA. ¿Y su marido?

DONCELLA 2. Es viuda y sin hijos.

AMO. ¿Y su nombre?

DONCELLA 1. Es una señora principal y rica de Castilla la Vieja. Pero su nombre... Traemos órdenes de no llamarla sino Señora Peregrina (IV, 03:30-03:55).

${ }^{14} \mathrm{Al}$ decir de Lee (2005: 49), la Señora Peregrina es la verdadera heroína femenina de la novela que, en contraste con su hija, «embodies the heroine of the hagiographical narrative of saints, a subspecies of the romance genre». Aquí, la madre de Constanza viste un hábito adornado con dos conchas de Santiago que no ofrecen duda de su condición. La figura del peregrino adquiere gran relevancia en la novela bizantina del Barroco (Sandoval, 2019: 32). Cervantes no se entregaría de lleno a la tradición etiópica hasta unos años después (Trabajos de Persiles y Sigismunda, 1617), pero sí que hizo sus pinitos en las Ejemplares. Prueba de ello es La española inglesa, en la que Isabela y Ricaredo deben superar una serie de obstáculos, dentro y fuera de su patria, para volver a reunirse.

${ }^{15}$ En términos de Genette (1989: 284), «llamaremos metadiegéticos a los acontecimientos contados en el relato [...], en segundo grado». 
Señores míos, los cielos me son testigos que sin culpa mía me hallo en el riguroso trance que ahora os diré. Yo estoy preñada, y tan cerca del parto que ya los dolores me van apretando. Ninguno de los criados que vienen conmigo saben mi necesidad ni desgracia; a estas mis mujeres ni he podido ni he querido encubrírselo. Por huir de los maliciosos ojos de mi tierra, y porque esta hora no me tomase en ella, hice voto de ir a Nuestra Señora de Guadalupe; ella debe de haber sido servida que en esta vuestra casa me tome el parto; a vosotros está ahora el remediarme y acudirme, con el secreto que merece la que su honra pone en vuestras manos (77-78).

SEÑORA PEREGRINA. Me hallo en el riguroso trance que ahora os diré. AMO. Os escuchamos.

SEÑORA PEREGRINA. Me hallo tan cerca del parto que los dolores ya me van apretando. Ninguno de mis criados sabe mi necesidad ni mi desgracia.

AMA. ¿Cómo lo habéis podido ocultar?

SeÑora Peregrina. Con la ayuda de mis dueñas. En ellas me he confiado. En vosotros está ahora el remediarme y acudirme con el secreto que merece la que su honra pone en vuestras manos. AMO. Confiad en nos (IV, 04:51-05:24).

También los dos protagonistas, Constanza y Avendaño, contrastan lo suyo respecto a sus modelos. En el texto de Cervantes, la ilustre fregona era una mujer un punto pasiva. De sus gestos (mínimos) apenas se desprenden rasgos definitorios. Se limita, por fin, a abrillantar la plata, obedecer y desdeñar ${ }^{16}$. Maestro (2007: 192-195) sostuvo que:

Constanza se nos presenta como la perla del muladar. Deseada e indiferente, es la criatura más inverosímil de la novela que lleva sus atributos al título mismo de la narración. [...] Hay que decirlo directamente: Constanza no es un personaje, es un arquetipo. La ilustre fregona es una mera figura retórica en la sintaxis de la novela, y

${ }^{16}$ Barrenechea (1962: 201). También se han pronunciado sobre este particular AvalleArce (1985: 11), Montero Reguera (1993: 354), Zimic (1996: 278) y Sevilla Arroyo y Rey Hazas (1997: XXII). 
no un personaje dotado de relieve [...], ni siquiera de personalidad propia. [...] Su vida es resultado de inercia moral. No habla, no ve, no oye...

Luego Constanza no trasciende en La ilustre fregona el papel de actante objeto, según las categorías de Greimas ${ }^{17}$. Así, nada extraña que los responsables de esta adaptación quisieran insuflarle algo más de vida. La primera oportunidad en la que veremos a los protagonistas en el cuarto capítulo sigue a la revelación del origen de la fregona: Constanza (Teresa Rabal) trenza sus cabellos en una suerte de pajar, haciendo gala de una coquetería que no le conocíamos a su homónima cervantina. A su espalda, irrumpe Avendaño (Emilio Gutiérrez Caba), que le espeta: «iPicarona, embustera, me habéis engañado!»(IV, 07:40). Y ella le ataja sorprendida: «Tomás! ¿Qué veis en mí para hablarme con palabras tan ofensivas?» (IV, 07:53). Al darse cuenta de que Constanza lleva abierto el primer botón de la camisa, el caballero replica: «Veo mucho, y tened la bondad de cubríos, que no conviene que vea tanto». Llegados a este punto, la moza acaba por estallar: « Tomás, me habéis ofendido! Además, sois un interesado y un aprovechado. ¡Idos al diablo!» (IV, 08:00). Solo entonces, el galán le explicará que tales cargos se derivan de la visita del Corregidor, durante la cual este quiso concertar la boda de Constanza con su hijo Perico. La fregona lo niega, pero sus razones son interrumpidas por los mesoneros, que venían en su busca. La pareja se ve obligada a ocultarse detrás del pajar hasta que no haya moros en la costa; lo que no impide que, una vez que los tutores de Constanza «hacen mutis», ella blasone de su honestidad: «Ni al hijo del Corregidor ni al rey de las Galias lo cambiaría por quien yo sé. [...] Y para daros una prueba, besadme en la frente» (IV, 09:25).

Este episodio permite extraer dos conclusiones. En primer lugar, Constanza ha debido de dar ya alguna señal que le revelara a Tomás que su amor era correspondido; de lo contrario, no se habría atrevido a recriminarla. No se trata, pues, de una moza esquiva, sumisa y recatada, sino de una adolescente algo altiva (fruto sin duda de su alcurnia) y más que

${ }^{17} \mathrm{El}$ objeto es aquel actante que se limita a recibir la acción. En virtud del mismo esquema (Greimas, 1974: 263-293), tendríamos a Avendaño como sujeto (el que realiza la acción) y a Carriazo como adyuvante (el que ayuda al sujeto a la consecución de su deseo). 
discreta, pero también vulnerable a las armas de Cupido. De las tres actividades que Constanza desempeñaba en el texto base, dos de ellas (obedecer y desdeñar) se transgreden en la serie de TVE: a) desafía las normas de sus padres adoptivos, citándose a escondidas con Avendaño; y b) acepta gustosa sus requiebros. Por otro lado, si Cervantes diseñó una Constanza que simbolizaba el sol alrededor del cual giraba toda su historia, esta función tampoco parece registrarse en el trasvase de Ibáñez; no al menos en su quinta entrega.

Aunque, según Zimic (1996: 271), resulta impropio considerar el amor que aparece en la novela como «ideal, platónico, en el sentido clásico de una aspiración pura, [...] el de Avendaño no es diferente, en esencia, al de otros enamorados de Constanza». Y esto es así porque se limita a mirarla a distancia, el único remedio para paliar su indiferencia. El Avendaño televisivo, en cambio, se atreverá exhibir otras artes ante una Constanza muchísimo más receptiva.

Detengámonos ahora en un episodio clave que apenas llega a aparecer en pantalla: la confesión de don Diego de Carriazo (padre) sobre el estupro del que nació la protagonista. Cervantes no tiene pelos en la lengua a la hora de admitir los pecados de este caballero, confesados además en primera persona:

[...] era la hora de siesta cuando llegué a su alcázar [...], subí sin topar a nadie hasta el mismo aposento donde ella estaba durmiendo la siesta sobre un estrado negro. [...] cerré tras mí la puerta, y, llegándome a ella, la desperté; $\mathrm{y}$, teniéndola asida fuertemente, le dije: «Vuesa merced, señora mía, no grite, que las voces que diere serán pregoneras de su deshonra» (85).

Pues bien, resulta casi imposible deducir la gravedad de los hechos en la versión que nos ofrece la cinta de Ibáñez y Cotanda:

De lo que ocurrió no tuvo ninguna culpa. Fue solo mía. Viuda ella y viudo yo, intenté reparar mi daño, pero fue inútil, pues nunca supe de ella hasta su muerte. Tan olvidada del mundo quiso vivir (VI, 14:07).

Nada explica Cervantes de la viudez de este violador ni de sus intenciones de reparar el daño; es más, nos informa justo de lo contrario: «esta señora se mudó de aquel lugar a otro, y, sin que yo jamás la viese, ni lo procurase, se pasaron dos años, al cabo de los cuales supe que era muerta» 
(86). Estamos, pues, ante una versión dulcificada de don Diego: padre de un simpático aspirante a pícaro y de la bella y despierta Constanza, sus lazos familiares resultan moralmente confusos y el final feliz, del que el abusador saldrá impune, del todo inaceptable. Para Zimic (1996: 278), sin embargo, este contraste entre la calidad humana de los hijos y la de su progenitor cumple un papel dentro del relato, toda vez que viene a demostrar que no existe determinación de sangre ni de linaje. Y lo mismo vale para Carriazo, ajeno a la fascinación femenina y que, a pesar de haber crecido en un ambiente regalado, sucumbe al impulso de la picaresca.

Un detalle que aquilata la verosimilitud de esta adaptación es que la fregona reacciona con mayor naturalidad que en la novela cuando descubre su origen. En el texto base, Constanza, «toda turbada y temblando, no supo hacer otra cosa que hincarse de rodillas ante su padre; y, tomándole las manos, se las comenzó a besar tiernamente, bañándoselas con infinitas lágrimas» (88). Por el contrario, la actriz Teresa Rabal permanece aquí seria y algo contrariada, hasta el punto de rehusar los cariños de su padre. Solo se agachará para besarle la mano, y don Diego replica: «Hija mía, levantad, pues soy yo quien os debería pedir perdón de rodillas» (IV, 15:30). Es ahora cuando la protagonista, mientras evita la mirada paterna, se pronuncia en estos términos: «No sé qué responder. Estoy realmente confusa» (IV, 15:38). Constanza se reserva la emoción (sincera) para despedirse de aquellos que la han criado. Tras su marcha, como era previsible, los viejos posaderos quedan devastados, pero se consuelan pensando en sus futuras visitas.

La siguiente escena pone el acento sobre la Argüello y la Gallega. Aunque ligeramente favorecidas en la serie, procuran respetar sus modelos librescos y se afanan en doblar la colada -más tarde las veremos pelando patatas $-{ }^{18}$. Luego entra Avendaño, que se había escondido de su padre, pero regresa en pos de Constanza. Tropezará aquí con el amo sevillano, que lo advierte de la ausencia de su dueña:

18 «Vive Dios, amigo, que [la Argüello] habla más que un relator y que le huele el aliento a rasuras desde una legua: todos los dientes de arriba son postizos, y tengo para mí que los cabellos son cabellera; y, para adobar y suplir estas faltas, después que me descubrió su mal pensamiento, ha dado en afeitarse con albayalde, y así se jalbega el rostro, que no parece sino mascarón de yeso puro» (51-52). Estas mozas de mesón se hallan «en claro contraste dialéctico con la fugacidad inmaculada -que nunca mariológica- de la ilustre fregona» (Maestro, 2007: 191). 
AVENDAÑo. Unas fiebres me obligaron a guardar cama en casa de un amigo. Después me di cuenta de que aquí tenía una obligación que cumplir y me di priesa en volver.

Amo. Decidme la verdad, Tomás, ¿cuál es esa obligación a la que hacéis mención?

AVENDAÑo. Pues... el libro de cuentas, la cebada.

Amo. Mirad que a mí es difícil engañarme. Desde que se marchó Constancica, yo tengo los ojos muy abiertos.

AVENDAÑo. ¿Qué decís, señor?

Aмо. ¿Crees que yo no me apercibía de vuestras comedias? ${ }^{19}$ $[\ldots]$

AMo. Mirad que no es mujer para vuestra condición.

AVENDAÑo. En su condición yo nunca tuve reparos. Tenéis que contarme todo lo que pasó. ¿Dónde se marchó? ¿Cuál fue el motivo? AMo. A nada de eso puedo responderos, pues solo añadiría la amargura a vuestro desengaño (IV, 19:00-19:16).

El amo sevillano no alcanza a precisar el paradero de Constanza, lo cual provoca un malentendido que dura hasta la última escena del quinto capítulo (y segundo de los supervivientes). Avendaño piensa que el amo conoce ya su identidad, de ahí que la mención de su diferencia de rangos sea interpretada erróneamente por el noble: este aduce que no le importa la condición de la fregona cuando el ventero sugiere que las prendas de Constanza son superiores a las suyas, o sea, a las de un pobre mozo de paja y cebada. Es por eso que Avendaño volverá a vestir sus opulentos ropajes, saldrá en busca de su amada y no regresará hasta dar con ella.

Carriazo, por su parte, solo aparece al final del cuarto episodio, donde mantiene esta breve conversación con la Argüello, que lo acosará hasta el desenlace:

ARGÜELLO. ¡Diego! ¡Ya sabía yo que volverías a mí!

CARRIAZO. Ya sabes que volver a ti sería haber estado, así que, como no he estado, tampoco se puede decir que haya vuelto.

ARGÜELLO. ¡Ay! Todo eso son trabalenguas que haces para confundirme (IV, 19:50-20:00).

${ }^{19}$ Repárese en el uso de este sustantivo («comedias»), pues, como se verá en el siguiente parágrafo, no es en absoluto casual. 
Esta escena denota que el papel de Carriazo se repite en la cinta de TVE sin cambios aparentes. El pícaro burgalés ejerce como contrapunto guasón del idilio de Constanza y Avendaño gracias a sus aventuras como aguador, industrioso tahúr y víctima de la Argüello. Como digo, su presencia se ciñe a este cuadro y a un diálogo con Avendaño en el que su camarada le revela que su corazón pertenece ya a Constanza ${ }^{20}$. Carriazo declarará entonces, no sin algún reparo, que no podrá acompañarlo, pues debía presentarse ante su padre para solicitar su perdón. No obstante, en otras estampas de los capítulos IV y V se añaden datos que sugieren que el texto base tuvo su peso en la adaptación. Avendaño sortea a su progenitor en el mesón donde se alojaba Carriazo, lo cual indica que la persecución que este había sufrido por parte de la Argüello se extremó hasta el punto de hacerle cambiar de vivienda (igual que en el relato de las Ejemplares). Del mismo modo, ya en el siguiente episodio, el Corregidor evoca la famosa pulla «Daca la cola, Asturiano» (V, 01:32), con la que los toledanos hacían rabiar al aguador (Montero Reguera, 1993: 343). Luego es harto probable que también llegara a rodarse aquel en el que Carriazo pierde «un asno por partes» en el juego, pero se niega a entregar la cola ${ }^{21}$. Lo que tampoco obsta para que sufra un cambio significativo, fruto de las ampliaciones de la entrega final de esta serie, acerca de las cuales discurriré a lo largo del siguiente epígrafe.

${ }^{20}$ Carriazo pregunta a su amigo si Constanza ha salido por «las puertas de Toledo». Avendaño responde que, a juzgar por las huellas del carruaje, «tantas veces como salió volvió a entrar» (V, 07:05). No sabemos si la alusión a estas puertas entraña aquí un sentido larvado, pero está claro que en el siglo XVI las mujeres que las frecuentaban tenían fama de prostitutas. Recuérdese que el Lazarillo (o mejor, Lázaro González Pérez) juraba «sobre la hostia consagrada que [mi esposa] es tan buena mujer como vive dentro de las puertas de Toledo» (Anónimo, 2012: 134-135). Así, «la defensa de Avendaño frente a las insinuaciones de su amigo da a entender precisamente que Constanza no es "mujer de buen fregado" y no se distrae en otras cosas que sus honestas tareas. [...] Al momento de producirse la anagnórisis, el padre interroga capciosamente a la Gallega, para tomar conocimiento previo del comportamiento y virtud de su hija: "Luego esta niña, a esta cuenta, debe de dejarse manosear y requebrar de los huéspedes". [...] "Dejarse manosear" es una alusión más pasiva, pero también una forma más directa (y que responde a una perspectiva masculina tradicional) de referirse a la mujer "que se refriega con todos" mencionada por Covarrubias»(González Briz, 2013: 4).

${ }^{21}$ Señala Checa (1991: 42): «Como imagen destacada del subargumento picaresco de La ilustre fregona, la cola del asno adquier[e] en él un valor emblemático». 


\section{SUCEDIÓ UNA NOCHE: EL ENREDO}

Como se ha puesto de relieve, el episodio V es la secuela natural de varios desarrollos de la historia. Sánchez Noriega (2000: 140 y 200-201) los divide en tres: a) desarrollos completos de acciones implícitas o sugeridas en el texto; b) desarrollos de acciones breves y de rasgos de personajes que no figuraban en el original; y c) desarrollos breves de acciones de contexto respecto a la acción principal. En esta adaptación de La ilustre fregona, se observan ejemplos de cada uno de ellos.

Respecto al primero, la cinta de Ibáñez muestra el proceso que culmina con los tres matrimonios anunciados por el narrador al final de su novelita:

entre el Corregidor y don Diego de Carriazo y don Juan de Avendaño, se concertaron en que don Tomás se casase con Constanza, dándole su padre los treinta mil escudos que su madre le había dejado, y el aguador don Diego de Carriazo casase con la hija del Corregidor, y don Pedro, el hijo del Corregidor, con una hija de don Juan de Avendaño; que su padre se ofrecía a traer dispensación del parentesco (89).

Además de los desposorios, Cervantes explicita que los burgaleses residieron un mes en casa del Corregidor antes de regresar a su rincón nativo. Por ello, no sorprende que dicha estadía y tan feliz desenlace se alearan, con una pizca de imaginación, para engrosar el último capítulo.

Al hilo de la segunda categoría de Sánchez Noriega, los protagonistas de las tramas ampliadas en el quinto episodio de La ilustre fregona serán las futuras esposas de Perico y Carriazo, cuyos nombres ni siquiera se mencionaban en la novela. Aquí atienden por Cristina y Dorotea.

Por último, los desarrollos breves de acciones de contexto se cifran en multitud de pequeñas pláticas que aclaran la peripecia. Por ejemplo, cuando el Corregidor pregunta a Carriazo si aquello de «daca la cola» que dicen en Toledo tiene que ver con él, el noble responde: «Sí, en efecto. En mis días de aguador me hice llamar Asturiano y lo de la cola, "daca" o "dame", fue por el lance que he referido" (V, 01:43). Este comentario brinda al público el significado de dicho estribillo, el cual no precisaría de glosa en el contexto en que lo empleó Cervantes. Así pues, me ocuparé 
de los dos primeros tipos de desarrollo, que son los que permiten un análisis más sugestivo y proporcionan información sobre el tipo de variación.

Para empezar, detengámonos en las nuevas damas. Dorotea, la hija del Corregidor y hermana de Periquito, parece la más astuta, traviesa y viva de las dos. Por eso invita a Cristina, asaz morigerada, a transgredir el decoro en su seducción de Perico. Bien mirado, se antoja difícil pensar en un perfil más oportuno para la «cazadora» del pícaro Carriazo.

Dicho eco venatorio no es gratuito, pues el último plano de la serie captura la cuerna de un ciervo en el salón del Corregidor (Fig. 5) ${ }^{22}$. Carriazo la observa con interés y celebra la puntería de su futuro suegro, quien aclara entre risas que el diestro montero no había sido él sino su heredera: "Muy buena tiradora. Y de montar a caballo...» (V, 19:50). A nadie se le escapa que bajo dicho comentario late un guiño sexual, amén de configurar el estatuto de Carriazo como «presa», cobrado ya por Dorotea, Diana triunfante ${ }^{23}$.
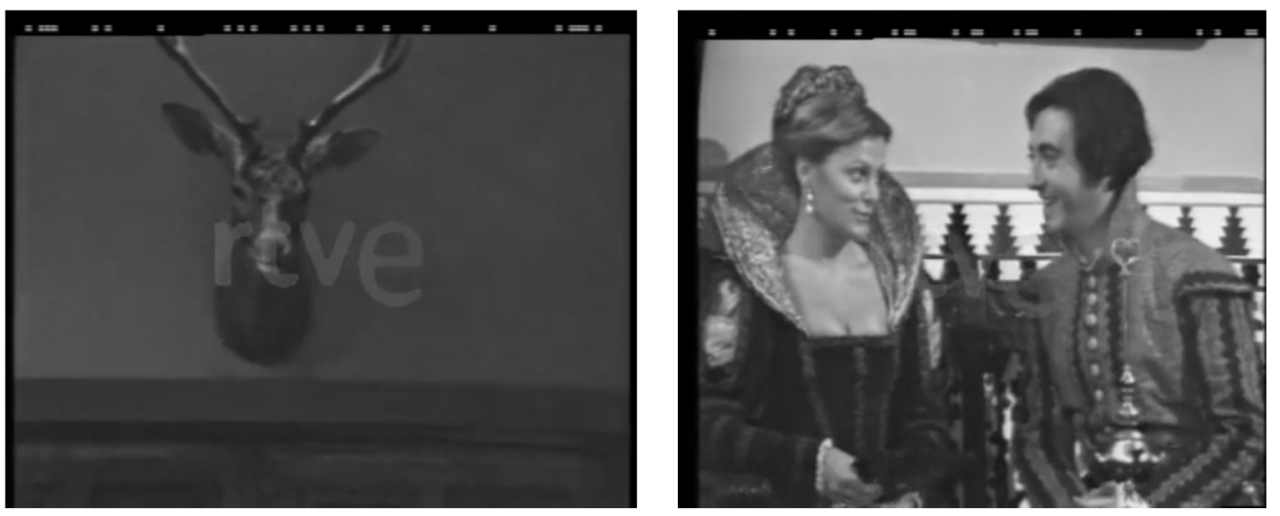

Figura 5

Figura 6

El cortejo -o mejor, la trampa- de esta pareja no es menos sugestivo que la construcción del personaje femenino. Carriazo y Dorotea se quedan a solas en casa del Corregidor. La dama se acomoda en un diván e

${ }^{22}$ Dicha cuerna quizás entrañe una ironía sobre próximas infidelidades.

${ }^{23}$ Sobre las «monterías de amor», véase Bonilla Cerezo (2007: 163). 
invita al caballero a sentarse a su lado (Fig. 6). Carriazo se muestra nervioso, fuera de control, zarandeado por el descaro de la muchacha. Y tiene lugar el siguiente diálogo:

Dorotea. Os digo [que os sentéis a mi lado] porque sé que sois un caballero, porque, si fuerais un pícaro...

CARRIAZO. ¿Qué?

Dorotea. Os daba una oportunidad en exceso imprudente... ¡Quedaba poco menos que en vuestras manos!

CARRIAZO. Sí, sí, sí, ya... Pero no temáis. [...] ¡Dorotea!

DOROTEA. ¿El qué?

CARRIAZO. ¿Y si yo no fuera... tan caballero?

DOROTEA. ¿Queréis decir... si fuerais un pícaro?

CARRIAZO. ¡No, no, no! Tanto no.

DOROTEA. ¿Entre pícaro y caballero?

CARRIAZO. Sí, sí. ¿Qué pensaríais?

DOROTEA. También podría ser que una dama se disfrazase y tuviese aventuras picarescas. ¿No lo habíais imaginado? (V, 10:42-11:58) ${ }^{24}$.

Durante esta conversación sale a relucir la naturaleza híbrida de Carriazo, quien ya en la novela «is presented as a master of more than one particular social discourse, for such mastery is crucial to his successful disguising and his skillful navigation through the lower reaches of society» (Clamurro, 1987: 48). Cervantes juega en La ilustre fregona con el tipo de pícaro que había concebido Alemán en el Guzmán de Alfarache (1599-1604) y lo contrahace. Frente a la tradicional genealogía vil que subrayara Rey Hazas (2003) para los herederos del Lazarillo, Carriazo es aquí un truhan de noble cuna y espolea un tipo de historia en el que «dos formas de vida pueden convivir en un solo personaje, mucho más complejo y significativo, pues [revoca] dos aparentes oposiciones: la virtud y la libertad» (Loeza, 2012: 88). Nada nuevo bajo el sol. En cambio, lo original del guion de Cotanda es el añadido del componente amoroso gracias a Dorotea. Está claro, de acuerdo con el diálogo que acabo de reproducir, que nos hallamos ante dos sujetos de la misma calaña. Ninguna otra mujer -y menos una virtuosa, discreta y esquiva, como su propia

${ }^{24}$ Se trata de un modelo algo antitético del acuñado por Castillo Solórzano, cuyas protagonistas empiezan siendo pícaras y terminan mejorando de posición, como la $\mathrm{Ru}$ fina de La garduña de Sevilla y anzuelo de las bolsas (1642). Véase Ruffinatto (2019). 
hermana- hubiera conseguido que el pillastre de Carriazo olvidara sus almadrabas: ha dado con su alma gemela e incluso ve en su prometida la ocasión de prorrogar sus fortunas, a partir de ahora en pareja. Dorotea es para Carriazo la compañera de picardías que Avendaño no quiso ser.

Tras esta insinuación, Dorotea abandona divertida la alcoba, dejando a su galán en vilo. Y por la otra puerta entrará el Corregidor, que se burla del caballero:

CORREGIDOR. (Ríe) Muchacho, sois vos quien no sabéis la realidad. [...] A [Dorotea] le gustan las bromas, lo confieso. Pero puedo juraros que, por ventura mía, es la más honesta muchacha que pudierais encontrar. [...] Eso sí: sincera con su padre. Por eso no tuvo reparos en confesarme en cuál aprecio os tenía y que intentaría...

CARRIAZO. ¿El qué?

CORREGIDOR. Eso lo sabréis vos mejor que yo.

CARRIAZO. ¡Ah! ¡Ahora lo comprenden mis entendederas! Lista es, pues faltó poco para sacarme de mis cabales. [...]

CORREGIDOR. Shh. ¡Id con cuidado con lo que decís! [...] ¡El matrimonio! ¿No le teméis? Dorotea, estoy seguro, os ama hasta el punto de... (V, 12:54-14:11).

Dorotea aparecerá ahora fingidamente dolida y preocupada por su festejador: «¡Ay, basta ya, padre mío! ¿Qué pensará Diego ahora?» (V, 14:12). Y Carriazo declara: «Yo pienso que sería el más feliz de los mortales si vuestra hija... Quiero decir que... Que no me salen las palabras... Que...» (V, 14:19). Entonces, la dama retira la cabeza del hombro de su padre y, ya «recobrada», inquiere:

DOROTEA. ¿Entiendo que pedís mi mano?

CARRIAZO. Sí. Creo que con ello llevo ganancia (V, 15:25).

Todos prorrumpen en risa. Carriazo ha caído ya en el cepo, aunque, a juzgar por su último apunte, parece que del todo a sabiendas. La historia cobra así mayor vuelo, profundizando en el carácter de un Carriazo con ansias de libertad. Cervantes nos dejaba en cambio con la incertidumbre de saber cómo encajó la noticia de sus bodas, más aún en el caso de un joven que ha manifestado su absoluta indiferencia hacia las mujeres: 
El matrimonio final de Carriazo es el que resulta menos significativo de los tres que resuelven el ingreso a la madurez de los protagonistas y su reintegración a las exigencias de su estado y condición [...] no responde a ninguna demanda ni significa ninguna reparación. Ni siquiera logra borrar por completo su pasado, ya que la única sombra que se cierne sobre el final feliz es el temor del antiguo aguatero de que, en cualquier momento, reaparezca el recuerdo de «la demanda de la cola» y aun remanezca «en alguna sátira» (González Briz, 2013: 95) ${ }^{25}$.

El perfil de Cristina es bien distinto. Su espíritu se asimila al de su hermano Avendaño, tan mesurado como sentimental. Desde el principio bebe los vientos por Perico, antiguo aspirante al corazón de Constanza. Para atraerlo, le asistirán en calidad de celestinas Dorotea y la antigua fregona. Conocedoras de la predilección que el hijo del Corregidor sentía por las venteras, deciden que la única forma de cautivarlo será haciendo que Cristina finja ser una de ellas ${ }^{26}$. Con este pretexto, Constanza le pide al mesonero que cite al hijo del Corregidor en la reja de la posada ${ }^{27}$. Llegada la hora, Cristina acude y se oculta tras una celosía:

CRISTINA. ¿Quién llama?

PERICO. Un hombre.

CRISTINA. ¿Y qué nombre lleva el que llama?

PERICO. El que ama.

CRISTINA. ¿Y ese hombre no busca a Constanza?

PERICO. Sin esperanza. Y como es verdad que no la conozco, justo es que encuentre en vos lo que ella nunca me dio.

CRISTINA. ¿Esperanza?

PERICO. Con ello me conformaré.

CRISTINA. Pero no me conocéis

PERICO. Vos de mí sí que sabéis. Y puesto que accedéis a escucharme, yo os daré compensación.

${ }^{25}$ Véase también Casalduero (1974: 192).

${ }^{26}$ Constanza deja claro que no solo lo intentó con ella: «Es aficionado a las mozas de mesón [...]. Estoy segura de que no fue a mí la única moza a la que rondó» (V, 05:01). El amor de Perico, que en la novela parecía sentir un afecto puro por Constanza, se banaliza aquí considerablemente.

${ }^{27}$ Esta escena forma parte de una de las costumbres de la época: «ventanear» $\mathrm{O}$ «hacer ventana» (Castilla Pérez, 2003). 
CRISTINA. ¿A una moza de mesón?

PERICO. ¿Es esa una sinrazón?

CRISTINA. No lo puedo yo decir (V, 15:20-15:49)

Perico, hechizado por el misterio, la dulce voz y acaso la garantía de que Cristina se muere por sus huesos, no podrá ya olvidarla. Le entrega entonces un anillo como prenda para asegurarle que volverá a rondarla ${ }^{28}$. He aquí, pues, el segundo caballero preso de las tretas mujeriles.

La serie se cierra con una anagnórisis múltiple. Recordemos que hasta ahora los personajes han ido apareciendo por grupos en los distintos espacios. La no coincidencia de todos permitía el mantenimiento de los engaños y las confusiones que sirven de nudo al capítulo V: Avendaño sigue en busca de Constanza y se niega a ver a su padre hasta que la traiga de vuelta, ajeno a que tanto su progenitor como su dueña se hospedaban en el mismo mesón; Perico desconoce la verdadera identidad de la moza porque nunca antes había reparado en su figura. En la última escena, entra decidido al salón para comunicarle a su padre sus planes matrimoniales. El Corregidor se escandaliza por la condición de su posible nuera $\mathrm{y}$, justo en ese momento, Cristina irrumpe en el cuarto y se identifica como la causa de sus trabajos. Perico la reconoce gracias al anillo que le había entregado durante su primera entrevista y se sella así el compromiso.

El primogénito del Corregidor, si bien aparecía ya en la novela, sufre aquí una notable transformación. Blanco de las burlas del texto -y lo mismo rige para las demás recreaciones audiovisuales-, se mofarán de él en la venta por cortejar a una criada y dedicarle sonetos. Su papel está ligado a la comicidad, llegando en otros filmes (los de Pou y Sánchez Enciso) a concluir su peripecia como el "galán suelto», que, al decir de Serralta (1988: 12), es el antepasado cómico del figurón ${ }^{29}$.

También Avendaño se persona en la sala y rechaza el desposorio -orquestado por su padre- con la hermana de Carriazo, alegando su inmarcesible afecto por la fregona. El Corregidor le ofrecerá su ayuda para

${ }^{28} \mathrm{El}$ anillo suele desencadenar enredos o bien la anagnórisis en el género de la comedia nueva. Algo similar ocurrirá en esta adaptación de La ilustre fregona, pues el anillo será el objeto que le permite a Perico reconocer a Cristina como su amada cuando esta ha recobrado su verdadera identidad.

${ }^{29}$ Véase asimismo Lanot y Vitse (1976: 208). 
encontrarla y solicita más datos sobre la joven. Pero Tomás no sabe su apellido y se queda algo taciturno, pensando en cómo localizarla. En ese preciso instante, se escucha la voz de Constanza, que entra en la habitación: "Me conocen como la ilustre fregona»(V, 19:19). Una vez se han despejado todas las incógnitas, se consuma el happy ending.

Hasta aquí el resumen de la serie. Es necesario, empero, abundar en la naturaleza del capítulo $\mathrm{V}$ y de la tradición de la que se nutre. Como he argumentado, los varios desarrollos de la historia y sus personajes confluyen en los tres idilios que suben al altar. Bien es verdad que la chispa entre Constanza y Avendaño se deriva del texto base y se repartiría a lo largo de los cuatro episodios anteriores. Sin embargo, es el último que muestra la fragua de la complicidad entre las otras parejas: Carriazo y Dorotea, por un lado, y Perico y Cristina, por otro.

Quiso la suerte que en sus orígenes hubiese un género fuertemente ligado al cine en su condición de espectáculo ${ }^{30}$ y cuyas tramas servían, precisamente, para narrar «el misterio de cómo han llegado [un] hombre y [una] mujer a [ese] compromiso personal, social y sacramental que es el matrimonio" (O'Connor, 1992: 164). Este género no es otro sino la comedia de enredo, la cual tiene «como única motivación realmente seria el amor» (Oleza, 1990: 210).

Pero no cometamos la torpeza de atribuir la calidad del desarrollo solo al talento de Cotanda. Sin duda, el texto cervantino posee una serie de características que hacen que la transición hacia la «comedia de enredo» discurra de manera natural; por la sencilla causa de que, en la época en que se escribió La ilustre fregona, la comedia y la prosa breve de ficción participaban de una misma horma, pues «lo fluctuante de las fronteras dentro el terreno de las ficciones hace que entre géneros que hoy diferenciamos de modo evidente no existiese de hecho una abierta

${ }^{30}$ El teatro siempre ha contribuido a la evolución de las formas audiovisuales. Lo hizo con el cine, a principios de siglo Xx, y años después también fue un buen padre para la televisión. López Mozo (2002: 158) recuerda cómo al principio la pequeña pantalla no era considerada más que «una especie de versión actualizada de la radio [...]. La incorporación del teatro fue muy importante para romper esa vinculación con la radio y abrió insospechados horizontes al nuevo medio de expresión, contribuyendo a dotarle de un nuevo lenguaje. Por su parte, el teatro ganó que el repertorio dramático universal entrara en miles de hogares españoles [...]». 
distinción» (Talens, 1977: 131) ${ }^{31}$. Al respecto, es de sobra conocida la cita de autor del Quijote apócrifo, que definió las Novelas ejemplares como «comedias en prosa» (Fernández de Avellaneda, 1972: 12); y no se pierda de vista la similitud que Lope de Vega (2006: 183) advertía en la función de ambos géneros: «Demás que yo he pensado que tienen las novelas los mismos preceptos que las comedias, cuyo fin es haber dado su autor contento y gusto al pueblo, aunque se ahorque el arte». Al margen de la trama amorosa, algunos elementos que acercan estos relatos a las piezas de enredo son la intriga enrevesada, las acciones simultáneas, los disfraces, las fugas y las apariciones. A renglón seguido, veremos los que aproximan La ilustre fregona y la adaptación de Ibáñez y Cotanda a las comedias de capa y espada.

Una serie de laberintos se resolverán a lo largo del último episodio y son fruto de no pocos desencuentros e imposturas: 1) Avendaño y Carriazo mienten sobre su posición y dicen ser Tomás Pedro y Lope Asturiano; 2) como el ventero ignora la verdad, oculta a Tomás lo ocurrido con Constanza; 3 ) para buscarla, Tomás peinará toda la ciudad, excepto la casa del Corregidor, en la que se hallaba la mujer y donde su padre pretendía que acudiese; 4) Cristina se hace pasar por fregona para ganar la voluntad de Perico; y 5) Dorotea juega picaronamente con la candidez de Carriazo.

Todos los protagonistas de la serie poseen un «espíritu jánico»: dependiendo de quien los mire o los seduzca, ocultan (o desconocen) una de sus caras. Avendaño es a la vez noble y mozo de taberna; Carriazo, caballero y aguador; Constanza, fregona y dama de tronío; Dorotea, señora y pícara; y Cristina, aristócrata y moza de mesón. El único que no se pliega a este paradigma es Perico; lo extraño en él, su doblez como respetable heredero del Corregidor, es su execrable afición por las venteras. Dichas dualidades componen un modelo alternativo al de la comedia de enredo, que solía basarse en sendos planos: el de los nobles -más dramático- y el de los criados -el diapasón cómico-. Aquí, en cambio, el desdoblamiento de la trama en señores y domésticos se hace innecesario,

${ }^{31}$ La estrecha relación entre la comedia y la novela ha sido estudiada sobre todo a propósito de las Novelas a Marcia Leonarda (1621/1624). Véanse Morínigo (1957), Yudin (1968), Baquero Goyanes (1983) y Gutiérrez Hermosa (1997: 168). 
porque el bifrontismo era ya inherente a todos y cada uno de los personajes $^{32}$.

No obstante, los varios embrollos sí que se solucionan en un final típico de la comedia nueva:

la asamblea de todos los actores en la última escena, con la celebración de las bodas múltiples la proclamación de las paces entre padres e hijos, familiares y seductores, es la gran ceremonia de la sumisión de los extraviados al orden y las instituciones (Oleza, 1990: 207).

Luego la ambigüedad, posible en las comedias, sobre todo en las de carácter irreverente, se distancia de los dramas de honor, condenados a perpetuar los dogmas sociales. De ahí también que en estas obras las mujeres asuman a menudo un papel muy diverso del acostumbrado en otros géneros $^{33}$. En La ilustre fregona de Ibáñez y Cotanda son ellas las que toman el mando y mueven la mayoría de los hilos: Dorotea caza a Carriazo, Cristina engaña a Perico y Constanza luce un carácter mucho más fuerte que el de su tocaya cervantina.

Dejando a un lado los lazos genéricos, huelga abundar en la diferencia elemental entre comedia y novela, la cual radica en la disposición del texto (dramático/en prosa). Es por ello que conviene reparar en las rimas internas del idilio en la reja entre Cristina y Perico, cuyo rodaje se acerca mucho más al modelo que pretende imitar -la comedia lopista- que al de La ilustre fregona ${ }^{34}$. Pero hay unas normas básicas a las que el teatro debía someterse: las relacionadas con el decoro. Aunque es verdad que la obediencia a las tres unidades dictadas por Aristóteles no era ya un requisito en el Barroco, sí que se convirtió en moneda común respetar al menos la de tiempo en las comedias de enredo. Según Arellano (1992: 169), esto induce a una «perseguida y forzosa inverosimilitud teatral» que

\footnotetext{
${ }^{32}$ Incluido el mismísimo don Diego de Carriazo, primero violador y luego gentilhombre.

${ }^{33}$ Véase Wardropper (1978: 226).

${ }^{34}$ Harina de otro costal es la «sustancia escénica» de la novelita de Cervantes. Aún en la Edad de Oro, se sucedieron tres versiones encima de las tablas: La ilustre fregona o el amante al uso (atribuida a Lope y publicada en la Veinticuatro parte perfecta de sus comedias, 1641), La hija del mesonero o la ilustre fregona (Diego de Figueroa y Córdoba, 1661) y La más ilustre fregona (manuscrito paródico firmado por José de Cañizares en 1709). Véase Vaiopoulos (2010).
} 
deriva, principalmente, de «las coincidencias y acumulación de sucesos en tiempo reducido [...] y no puede desligarse de la construcción laberíntica de la trama ingeniosa ni de la acumulación de enredos cuyos efectos potencia (Arellano, 1992: 167-168).

En la adaptación de Ibáñez, las tramas de Cristina y Dorotea comienzan y se abrochan en el capítulo $\mathrm{V}$, dentro de un tiempo interno que no supera las veinticuatro horas. Esto jamás habría sucedido en el texto base, pues la novela no se atiene a la unidad de tiempo; su propia naturaleza descriptiva le permite dilatar los sucedidos sin apenas estorbos ${ }^{35}$. Dicha antinomia entre la narrativa y el teatro desliga el quinto episodio del resto de la serie y hasta de su misma raíz ficcional, acercándola así a la comedia. El autor del Quijote nunca habría aglutinado tantos acontecimientos en un lapso tan corto, en esencia porque atentaría contra el principio de verosimilitud.

Cierto es que en La ilustre fregona figuraban una serie de lances de dudosa credibilidad, empezando por el azar de que Carriazo y Avendaño fueran a parar a la posada donde vivía la hermanastra del primero. No obstante, estos recursos vienen respaldados por otros tantos que aquilatan la historia: el paso del tiempo es uno de ellos, ya que logra, sin ir más lejos, que se robustezca la firmeza del amor que Tomás profesaba a Cons$\operatorname{tanza}^{36}$.

Si aceptamos la tesis de Riley (1981: 152), concluiremos que en Cervantes un evento extraordinario acompañado de verosimilitud resulta en admiración -o sea, en la consecuencia deseada. Por el contrario, uno extraordinario (como el enamoramiento instantáneo de cuatro jóvenes), sin verosimilitud estalla en risa; y Cervantes quería divertir, pero no provocar la carcajada. Su humor se asienta sobre los pilares de la ironía: trata del absurdo, sí, pero del inherente a nuestras vidas y no del anclado en la irrealidad. La comedia de enredo, empero, invita a regocijarse en los disparates, que son los mismos que la dotan de su pura razón de ser.

${ }^{35}$ Veamos un ejemplo: «En resolución, dentro de quince días estuvo fuera de peligro el herido, y a los veinte declaró el cirujano que estaba del todo sano; y ya en este tiempo había dado traza Tomás cómo le viniesen cincuenta escudos de Sevilla» (47).

${ }^{36}$ En La ilustre fregona se menciona la plaza de Zocodover, el Sagrario, el artificio de Juanelo, las Vistillas de San Agustín, la Huerta del Rey y la Vega, etc. Y la Posada del Sevillano existió de verdad. 
Este último es el gesto por medio del cual Cotanda echó su cuarto a espadas en el colofón de su libreto. No digo que la serie de TVE carezca de verosimilitud. No en balde, la actitud de Constanza ante la noticia de su concepción parece mucho más creíble, al menos para un público moderno, que la descrita por Cervantes. Como hemos visto, el desarrollo de los personajes se realiza con tino, pues a todas luces el guionista supo leer entre líneas la octava de las Ejemplares para deducir los caracteres de las dos damas ausentes: Cristina y Dorotea.

No obstante, sí que tomaría prestados algunos resortes de la comedia de enredo para pormenorizar el proceso que conducirá al casamiento múltiple descrito en la novelita. El quinto es un capítulo fresco, decididamente entretenido y que se tradujo en una «coda lopista» al epílogo de Cervantes. Aunque su factura no avenga del todo con la poética del texto base, La ilustre fregona de la dupla Ibáñez-Cotanda resultó una feliz apuesta de los directivos de TVE que a buen seguro congenió con el gusto de una audiencia cada vez más habituada a disfrutar en sus pantallas de un arte nuevo de ver comedias.

\section{BIBLIOGRAFÍA CITADA}

ANÓNIMO (2012): Lazarillo de Tormes. Ed. F. Rico. Madrid, Cátedra.

ARANDA ARRIBAS, V. (2017): «La ilustre (y muda) fregona de Armando Pou (1927)». Hispania Félix, 8, págs. 107-173.

ARANDa ARribaS, V. y Bonilla CEREzo, R. (2018): "El licenciado Vidriera visto por Fernández Santos: un palimpsesto cervantino». Piedras lunares. Revista jienense de literatura, 2, págs. 159-213.

AvalLE-ARCE, J.B. (1985): «Introducción». En Cervantes Saavedra, M.: Novelas ejemplares III. Madrid, Castalia, págs 7-34.

Baquero Goyanes, M. (1983): «Comedia y novela en el siglo XVII». En Serta philologica F. Lázaro Carreter. Madrid, Cátedra, vol. II, págs. 13-29.

BARRENECHEA, A.M. (1964): «La ilustre fregona como ejemplo de estructura novelesca cervantina». En Jones, C.A. y Pierce, F. (coords.): Actas del Primer Congreso Internacional de Hispanistas celebrado en Oxford del 6 al 11 de septiembre de 1962. Oxford, The Dolphin Books, págs. 199-206.

Bonilla CEREzo, R. (2007). "Sus rubias trenzas, mi cansado acento: ciervas, cazadoras y corcillas en la poesía de Góngora». En Roses, J. (ed.): Góngora hoy 
IX. «Ángel fieramente humano». Góngora y la mujer. Córdoba, Diputación de Córdoba, págs. 157-264.

CASAlduero, J. (1974): Sentido y forma de las Novelas ejemplares. Madrid, Gredos.

CASTILla PÉREZ, R. (2003): «Ronda y galanteo en algunas piezas de teatro breve». En Castilla Pérez, R. (coord.): Ronda, cortejo y galanteo en el teatro español del Siglo de Oro. Actas sobre el I Curso de Teoría y Práctica de Teatro, celebrado en Granada, los días 7-9 de noviembre de 2002. Granada, Universidad de Granada, págs. 153-165.

Cervantes SAavedra, M. (1978): El ingenioso hidalgo Don Quijote de la Mancha. Ed. L.A. Murillo. Madrid, Castalia.

- (1997): La ilustre fregona. Las dos doncellas. La señora Cornelia. Ed. F. Sevilla Arroyo y A. Rey Hazas. Madrid, Alianza.

CHECA, J. (1991): «El romance y su sombra: hibridación genérica en La ilustre fregona». Revista de Estudios Hispánicos, 25.1, págs. 29-47.

Clamurro, W.H. (1997): Beneath the Fiction: The Contrary Worlds of Cervantes's Novelas ejemplares. New York, Peter Lang.

Fernández de Avellaneda, A. (1972): Don Quijote de la Mancha. Ed. M. de Riquer. Madrid, Espasa Calpe.

GARCÍA DE CASTRO, M. (2002): La ficción televisiva popular: una evolución de las series de televisión en España. Barcelona, Gedisa.

GENETTE, G. (1989): Figures III. Barcelona, Lumen.

GERNERT, F. (2013): «La diversión de las segregadas: prácticas sociales y espacios textuales». En Albert, M. (dir.): Sociabilidad y literatura en el Siglo de Oro. Madrid, Iberoamericana-Vervuert, págs. 219-238.

GonZÁLeZ, L.M. y Medina, P. (eds.) (2017): Cervantes en imágenes. Donde se cuenta como el cine y la televisión adaptaron su vida y obra. Edición digital. Festival de Alcalá de Henares-Comunidad de Madrid.

GONZÁLEZ BRIZ, M.A. (2013): «Aventuras que cierran heridas: el camino hacia el matrimonio». Caracol, 6, págs. 80-101.

GREIMAS, A.J. (1974): Semántica estructural. Investigación metodológica. Madrid, Gredos.

GUTIÉRREZ HERMOSA, L.M. (1997): «La constitución de un "arte nuevo de hacer novelas": apuntes a una teoría de la novela corta». Exemplaria. Revista Internacional de Literatura Comparada, 1, págs. 157-177.

LANOT, J.R. y Vitse, M. (1976): «Éléments pour une théorie du figuron». Caravelle. Cahiers du monde hispanique et luso-brésilien, 27, págs. 189-213. 
LÁzARO, A. (2017) «Dos cabalgan juntos (Rodajes cervantinos en Castilla-La Mancha)». González y Medina (2017: s. p.).

LEE, C.H. (2005): «La Señora Peregrina as Mediatrix in La ilustre fregona». Cervantes: Bulletin of the Cervantes Society of America, 25.1, págs. 45-68.

LoEZA, A. (2012): «Una definición contrastada de la picaresca cervantina a partir de La ilustre fregona». En Boadas, S. et al. (eds.): La tinta en la clepsidra. Fuentes, historia y tradición en la literatura hispánica. Barcelona, PPU, págs. 79-88.

LoPe DE Vega, F. (2006): Arte nuevo de hacer comedias. Ed. E. García SantoTomás. Madrid, Cátedra.

LÓPEZ, F. (2009): Historias de la pequeña pantalla: representaciones históricas en la televisión de la España democrática. Madrid, Iberoamericana-Vervuert. LóPEz Mozo, J. (2002): «Teatro y televisión: ¿un matrimonio bien avenido?». En Romera Castilla, J. (ed.): Del teatro al cine y la televisión en la segunda mitad del siglo XX. Madrid, Visor, págs. 157-170.

Maestro, J.G. (2007): Las ascuas del imperio. Crítica de las "Novelas ejemplares» de Cervantes desde el materialismo filosófico. Vigo, Academia del Hispanismo.

Montero Reguera, J. (1993): «Cervantes y la verosimilitud: La ilustre fregona». Revista de Filología Románica, 10, págs. 337-360.

MoRínIGO, M.A. (1957): «El teatro como sustituto de la novela en el Siglo de Oro». Revista de la Universidad de Buenos Aires, 5, págs. 41-61.

OLEZA, J. (2007): «De venta en venta hasta el Quijote. Un viaje europeo por la literatura de mesón». Anales cervantinos, 39, págs. 17-51.

— (1990): «La comedia: el juego de la ficción y el amor». Edad de Oro, 9, págs. 203-220.

PARDO GARCíA, P.J. (2010): «Teoría y práctica de la reescritura filmoliteraria (a propósito de las reescrituras de The Turn of the Screw)». En Pérez Bowie, J.A. (ed.): Reescrituras filmicas: nuevos territorios de la adaptación. Salamanca, Universidad de Salamanca, págs. 45-102.

Rey HazAS, A. (2003): Deslindes de la novela picaresca. Málaga, Universidad de Málaga.

RiLeY, E.C. (1981): Teoría de la novela en Cervantes. Madrid, Taurus.

Rodríguez CuAdros, E. y HARo Cortés, M. (1999): Entre la rueca y la pluma. Novelas de mujeres en el Barroco. Madrid, Biblioteca Nueva. 
Romero-DíAz, N. (2013): «Del sarao zayesco a la carta agrediana. La sociabilidad cortesana femenina en la España de Felipe IV». En Albert, M. (dir.): Sociabilidad y literatura en el Siglo de Oro. Madrid, Iberoamericana-Vervuert, págs. 255-276.

RufFinAtTo, R. (2019): "Pícar@s que no dejan huella. La muerte del picarismo en la picaresca de Castillo Solórzano». Criticón, 136, págs. 73-90.

SÁNCHEz NoRIEGA, J.L. (2000): De la literatura al cine: teoría y análisis de la adaptación. Barcelona, Paidós.

SANDOVAL, P.A. (2019): El peregrino como concepto en las Soledades de Góngora. Alcalá, Universidad de Alcalá de Henares.

SEGUIN, J.C. (2015): «Las Novelas ejemplares en tiempos del cine silente». En Marigno, E. et al. (eds.): Cervantes creador y Cervantes recreado. Pamplona, BIADIG, págs. 249-279.

SERralta, F. (1988): «El tipo del 'galán suelto': del enredo al figurón». Cuadernos de teatro clásico, 1 , págs. 83-93.

Sevilla Arroyo, F. y Rey Hazas, A. (1997): «Introducción». Cervantes Saavedra (1997: I-LXXXI).

TALENS, J. (1977): La escritura como teatralidad. Valencia, Universidad de Valencia.

UTRERA MAcías, R. (2000): Film Dalp Nazarí. Córdoba, Filmoteca de Andalucía. VAIOPOUlos, K. (2010): De la novela a la comedia: las Novelas ejemplares de Cervantes en el teatro del Siglo de Oro. Vigo, Academia del Hispanismo.

WARDropper, B.W. (1978): La comedia española del Siglo de Oro. Barcelona, Ariel.

Wolf, S. (2001): Cine/Literatura. Ritos de pasaje. Barcelona, Paidós.

YUDIN, F.L. (1968): «The novela corta as comedia. Lope's Las fortunas de Diana». Bulletin of Hispanic Studies, 45, págs. 181-188.

ZIMIC, S. (1996): Las «Novelas ejemplares» de Cervantes. Madrid, Siglo XXI.

Victoria ARANDA ARRIBAS

Universidad de Córdoba imberetumbra@gmail.com 0000-0003-2913-3918 
